\title{
The politics of social assistance in crises
}

\author{
Jeremy Lind and Paul Harvey
}

February 2022

\section{Theme summary}

Social protection policies increasingly exist in crisis-affected settings. Their implementation is mediated by politics, resource constraints, and the attitudes and beliefs of those responsible for shaping policy. However, prevailing perspectives on the politics of social protection (incorporating social assistance) are largely limited to settings that are not characterised by protracted crises and conflict. Moreover, they do not consider relationships with humanitarian channels and providers of cash assistance, or seriously consider politics and more varied delivery arrangements at the sub-national level. The evidence base on the politics of social assistance in crises suggests that more granular understanding is needed of the political economy of social assistance, to discern what enables and constrains reforms that would lead to more effective, efficient, and sustainable support.

This brief summarises the state of what is known and what gaps there are in the evidence regarding how politics shape social assistance policy and implementation. It informs a future research agenda for assessing the dynamics and processes affecting how social assistance is allocated and to whom, including the roles and relationships between global, national, and subnational actors that influence patterns of allocation.

This thematic brief is a shortened version of two BASIC Research Working Papers. To explore this research theme in more detail please refer to:

Lind, J. (2022) Politics and Governance of Social Assistance in Crises from the Bottom Up, BASIC Research Working Paper 4, Brighton: Institute of Development Studies, DOI: 10.19088/BASIC.2022.004

Harvey, P. and Mohamed, H. (2022) Conflict and the Humanitarian and Development Nexus in Social Protection and Humanitarian Policies for Assistance in Crises, BASIC Research Working Paper 10, Brighton: Institute of Development Studies, DOI: 10.19088/BASIC.2022.010

A full list of the references cited in this brief can be found at the BASIC Research Zotero library. Implemented by
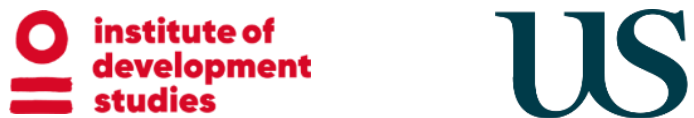

UNIVERSITY OF SUSSEX
UNIVERSITY OF WOLVERHAMPTON

\section{CIDT}

Better Assistance in Crises (BASIC) Research (funded by UKAid) aims to inform policy and programming on how to help poor and vulnerable people cope better with crises and meet their basic needs through more effective social assistance. All costs related to BASIC Research are covered by the UK Foreign, Commonwealth and Development Office. 


\section{State of the evidence and debate}

Social protection policies increasingly exist at national levels. Politics, resource constraints and the attitudes of those shaping policy influence their implementation. Donors and aid agencies, meanwhile, are committed to improving links between humanitarian cash and social protection, expanding social assistance in crises, and strengthening national systems.

Within these commitments, however, better understanding is needed of the political (and not just the technical) constraints in protracted crises - and of the enabling factors. The latter could allow more effective linkages across humanitarian, development and climate actors, more sustained financing, and potentially stronger national systems.

Social assistance policies of crisis-affected governments and aid agencies are prone to 'conflict blindness'. Government social protection policies in conflict-affected countries often make little mention of conflict. Particularly in Africa, evidence from relatively stable contexts suggests some resistance and scepticism within affected governments about investing more in social assistance due to concerns about dependency and affordability. Elite attitudes and understandings of poverty, dependency, and the role of assistance shape policies, eligibility, and approaches to targeting, conditionality, and financing of social assistance.

A limited literature considers the ways that local-level politics affect how people navigate and receive assistance, but these insights are rarely linked to programme design, policy, or capacity-building efforts. Local agency shapes the policy process as much as national-level actors and 'official politics'. It produces kaleidoscopic practices as formal ideas of delivery are adapted to suit local realities and power relations. Implementation becomes a political process of negotiation and recalibration - not simply a technical exercise.

Approaches such as 'rationality in context' (exploring the logics of local-level authorities delivering programmes) and the analysis of governance in crisis settings help to illuminate how social assistance is really targeted, taxed, diverted, and shared. They raise key questions over how assistance is provided, in whose interests, and how the provision of assistance affects poverty and vulnerability.

\section{Gaps in the evidence}

Prevailing perspectives on the politics of social protection are largely limited to stable settings, and do not consider relationships with humanitarian channels and providers of cash assistance. More dedicated analysis is needed of places characterised by contested public authority (and often non-recognised authorities); protracted displacement; uneven claims and rights to citizenship; threats and use of violence, and the significance of humanitarian provision. Efforts to expand social assistance systems must address the problems that non-state and/or non-recognised authorities pose for policy processes.

Very little research on social protection politics looks at sub-national political economies. How influence operates at the local level, through which connections, and the rationalities (or logics) of decisions affecting how social assistance is delivered and to whom - these all demand attention.

The nature of domestic politics - including how national political leaders relate with transnational policy actors and networks - determines which social protection programmes are adopted, when, and at what scale. Yet the evidence base is patchy concerning the precise mechanisms governing these processes, such as social contracts and taxation. This is true for both stable settings and protracted crises where domestic politics are inseparable from conflict and displacement. Understanding how social assistance is differentially allocated, or not, is thus crucial to understanding its implications for citizenship. So too is the relationship between taxation and social assistance provision within specific regions or particular groups. 
Social protection policies and strategies fail to see conflict dynamics. Some humanitarian strategies show an interest in engaging with social protection actors, yet the policy spaces and processes behind social protection systems are poorly understood.

Despite being mentioned in a large literature on social protection, capacity and coordination are not substantively assessed beyond a superficial diagnosis of problems. Few clear analytical frameworks exist for understanding capacity and coordination challenges - especially in fragile, conflict-affected settings, where capacity is assumed to be weak and coordination problematic

\section{Directions for research}

The evidence base on the politics of social assistance in crises suggests that more granular understanding is needed of the political economy of social assistance. This would illuminate what enables and constrains the reforms that would produce more effective, efficient, and sustainable assistance. Attention is required about patterns of differential incorporation and exclusion, and on regional, ethnic, and other differences in social assistance provision, including the political processes underpinning them.

\section{Research needs to:}

- Analyse the dynamics and processes affecting the allocation of social assistance, including the roles and relationships between global, national, and sub-national actors that influence patterns of allocation.

- Advance new applied thinking around patterns of social assistance allocation, taxation, and social contracts, across contexts with different public authority mixes, including non-recognised groups.

- Contribute towards the development of practical strategies and approaches for international actors to effectively engage with and strengthen systems at national and sub-national levels.

\section{Broad research questions:}

- What are the politics of social assistance in crises?

- How can international actors navigate national and sub-national dynamics to strengthen commitments for more effective and sustainable support to those in need?

\section{Sub-questions:}

- Is social assistance allocated uniformly across the societies being studied, or is it captured and allocated disproportionately to some groups or regions, excluding others? What policy or political processes underpin these patterns?

- What is the relationship between patterns of social assistance allocation and taxation?

- How is social assistance allocated and distributed differently between areas with different public authority mixes, including non-recognised authorities that exert control over sub-national areas and populations? What are the roles of international and sub-national actors therein?

- How does social assistance within protracted crises contribute to building, or eroding, conceptions of and attitudes to citizenship?

\section{Acknowledgements and Disclaimer}

This document was developed by the Better Assistance in Crises (BASIC) Research programme. BASIC is implemented by the Institute of Development Studies (IDS), the University of Sussex and the Centre for International Development and Training, funded by UKAid from the UK government. The views expressed in this document are entirely those of the authors and do not necessarily represent views or policies of the UK governments official policies.

(C) IDS copyright 2022. Copyright in the typographical arrangement and design rests with IDS.

This publication (excluding the logos) may be reproduced free of charge in any format or medium, provided that it is reproduced accurately and not used in a misleading context. The material must be acknowledged as IDS copyright with the title and source of the publication specified.

Published by IDS. 